\title{
How Much Should We Care About Changing Income Inequality in the Course of Economic Growth?
}

\author{
Gary S. Fields \\ Cornell University \\ March, 2007
}

\section{Keywords: Inequality, poverty, pro-poor growth}

\begin{abstract}
This paper asks how much we should care about changes in Lorenz curves and standard inequality measures when economic growth takes place. I conclude that these changes are of some importance but that other aspects of inequality and poverty are more important.

\section{$\underline{\text { Introduction }}$}

In December, 2006, the new President of Chile, Michelle Bachelet, convened a workshop on economic inequality. Chile has achieved a $4.2 \%$ annual rate of economic growth over the last thirty years, an enviable record indeed for a Latin American country. In the course of this economic growth, indigence and poverty have been falling continuously. Yet, Chile has one of the most unequal distributions of income in Latin America, which is the highest inequality region in the world, and income inequality in Chile remains, in the President's words, "stubbornly stagnant." This fact motivated her to convene a workshop on the question of how much should we care about income inequality. This paper, based on the keynote speech I delivered at that workshop, attempts to answer this question, not just for Chile but for the developing countries more generally.
\end{abstract}

Four aspects of income distribution may be distinguished. Income inequality involves comparisons between some incomes and others. ${ }^{1}$ Poverty analysis entails identifying who is poor and then quantifying the extent of poverty in the population. ${ }^{2}$

\footnotetext{
${ }^{1}$ This paper is limited to a discussion of relative inequality. Relative inequality is concerned with income ratios, not income differences. Thus, if all incomes grow by the same percentage, relative inequality is unchanged.

2 This paper addresses absolute poverty, which is based on a constant real poverty line, as is used internationally by the World Bank and by individual countries such as the United States. By contrast, relative poverty is based on a changing real poverty line - for example, in Europe, where the European
} 
Income mobility is about the changes in income or economic position when the same people are followed over time. ${ }^{3}$ Finally, economic well-being studies ask, when is one income distribution better than another? ${ }^{4}$

This paper discusses how much attention the inequality aspect of income distribution should receive as compared with the other three aspects. I begin by presenting data on poverty and inequality in the world at present and how these aspects of income distribution have changed in the course of economic growth. I then present my own views on the relative importance of inequality and poverty and then proceed to the title question.

\section{What We Know About How Various Aspects of Income Distribution Change in the}

\section{Course of Economic Growth?}

An estimated 1.1 billion people in the world live on less than one U.S. dollar per person per day in purchasing power parity (PPP) terms, and another 1.6 billion people live on between one and two U.S. dollars per person per day (World Bank, 2005). Thus, nearly half of humanity (44\%) are absolutely poor using this very modest poverty line. The number of people in poverty has changed little over the last ten years. What has changed is the number of people not in poverty - about one billion more of them - and therefore the proportion of people in poverty has fallen (International Finance

Union identifies as poor those whose incomes adjusted for household composition fall below $60 \%$ of the median.

${ }^{3}$ Six different notions of income mobility are used in the literature. They are time-independence, positional movement, share movement, directional income movement, non-directional income movement, and mobility as an equalizer of longer-term incomes. See Fields (2001) for a discussion of the first five of these and Fields (2005) for a discussion of the sixth.

4 "Better" is used here in either of two senses: 1) The participants face better economic prospects in one economy compared with another, or 2) An observer using a particular social welfare criterion judges one income distribution to have higher economic well-being than another. 
Corporation, 2000). Virtually all of these people live in the developing countries, and hence this paper focuses on the developing world.

Let us turn now to income inequality. ${ }^{5,6}$ The most commonly-used measure of income inequality is the Gini coefficient. ${ }^{7}$ The Gini coefficient of world income inequality has been estimated by various researchers to be between 0.62 and 0.70 . To give a sense of how high this is, the United Nations reports inequality figures for 177 countries, and only one (Namibia) has a Gini coefficient as high as the Gini coefficient for world inequality (United Nations, 2004, Table 14).

As for changes in income inequality, we can look both at world income inequality and at income inequality within countries. Concerning world inequality, by most accounts, it has been falling since 1990 and perhaps before (Martin Wolf, 2004; Branko Milanovic, 2005). This is because of the rising incomes throughout the income distribution in China and India. Milanovic (2005) presents a comprehensive survey of this literature. As for within-country inequality in the developing world, studies show about an equal division between countries where income inequality has been rising and those where it has been falling (Klaus Deininger and Lyn Squire, 1998; Fields, 2001).

The term "pro-poor growth" (or, as some prefer, "shared growth") is used to characterize the extent to which the poor share in such economic growth as takes place. The weakest definition is that growth is pro-poor if poverty falls when growth takes place ( Leipziger, 2005; Kraay, 2006). A somewhat stronger definition is that growth is propoor if the poor enjoy the same proportionate increases in income or consumption as do

\footnotetext{
${ }^{5}$ Throughout this paper, "inequality" refers to relative inequality, i.e., that which is based on ratios rather than differences.

${ }^{6}$ Three concepts of world inequality are used in the literature (Ajit Ghose, 2003; Branko Milanovic, (2005). "Inter-country inequality" is the inequality of per-capita GDPs, with each country counting with a weight of one. "International inequality" weights each country's per-capita GDP by its population size. Finally, "world inequality" estimates the distribution of income among persons regardless of their country of origin. It is "world inequality" that is most interesting and that is discussed in the text.

${ }^{7}$ The Gini coefficient ranges from zero to one, higher values signifying greater inequality.
} 
others (Ravallion, 2004). Stronger yet is the notion that growth is pro-poor if poverty falls by more than it would have if all incomes had growth at the same rate (Baulch and McCulloch, 2000; Kakwani and Pernia, 2000; Duclos and Wodon, 2004). Strongest of all is that growth is pro-poor if the poorest $20 \%$ of the population gets $20 \%$ of the benefits of growth (Harberger, 1998; Summers, 1998.) According to the evidence presented below, economic growth is nearly always pro-poor in the weakest sense and never pro-poor in the strongest sense. Given the ambiguity of the terms "pro-poor growth" and "shared growth," I shall not use them in what follows, but rather will talk explicitly about inequality, poverty, and economic well-being.

Of the many questions that might be asked about the relationship between income distribution and economic growth, five are paramount in my mind. First, what does theory have to say about the effect of economic inequality and poverty on economic growth? Second, what is the empirical evidence on the effect of economic inequality on economic growth? Third, looking in the reverse direction, what is the effect of economic growth on economic inequality? Fourth, what is the effect of economic growth on poverty? And fifth, what is the effect of economic growth on economic well-being?

In a book completed several years ago (Fields, 2001), I reached the following answers to these questions for the developing countries of the world for which we have data: ${ }^{8}$

First, theory is ambiguous about the effect of economic inequality and poverty on economic growth. While there are numerous theories in which economic inequality has a positive effect on economic growth, there also are numerous others in which the effect is negative.

\footnotetext{
${ }^{8}$ It is not that I am disinterested in the developed countries, but rather that the study of the developing countries is a big enough task in itself.
} 
Second, the international empirical evidence about the effect of economic inequality and poverty on economic growth is quite mixed. Some authors have found that economic inequality reduces economic growth, while others have found that economic inequality increases economic growth. The results are conclusively inconclusive.

Third, Kuznets' hypothesis that income inequality increases in the early stages of economic growth and then decreases is not a law or even a central tendency. About $10 \%$ of the country cases are consistent with Kuznets' inverted- $U$, another $10 \%$ support an ordinary $U$, and the remaining $80 \%$ exhibit no statistically significant tendency at all. What matters for inequality is not the rate of economic growth or the level of national income but the type of economic growth.

Fourth, the effect of growth on poverty is quite clear. When growth takes place, poverty nearly always falls. When poverty has not fallen, it usually is because economic growth has not taken place (and, sadly, what has taken place is economic decline).

And fifth, in each of five economies studied, economic growth has been shown to produce an income distribution that dominates the original one in the sense that for any given income amount, a smaller percentage of the population was below that amount after economic growth took place than before. ${ }^{9}$ The dominance of the post-growth distribution over the pre-growth one arises despite the fact that income inequality increased in four of the five economies.

These five findings convey quite different impressions from one another. If inequality increases with economic growth in half of the cases, then growth looks pretty bad. If poverty falls in the great majority of cases in which economic growth takes place, growth looks very much better. And if the post-growth income distribution dominates the pre-growth distribution each time that economic growth takes place (albeit for a very

\footnotetext{
${ }^{9}$ This type of dominance is called "first-order-dominance," which is equivalent to "rank dominance." See Fields (2001, Chapter 8) for definitions and further discussion.
} 
small sample of countries), growth looks even better yet. These different impressions come about because different aspects of the income distribution are emphasized when the different approaches are used.

It is precisely because each analyst has to decide which of these aspects of the income distribution to give the most weight to that we need to ask how much we should care about income inequality. The answer I shall give is a rather mixed one.

\section{Which Is the More Pressing Problem, Inequality or Poverty?}

To some observers, this question may make little sense. If the size of the pie is fixed, doesn't rising inequality necessarily imply falling incomes for the poor and hence rising poverty? The first part of the answer is that the size of the pie is not usually fixed. A majority of the world's economies are growing. The second part of the answer is that when inequality is rising, it could be because the rich (or more precisely, the non-poor) are getting richer while the poor are getting poorer. But then again, it could be that the poor and the non-poor are both getting richer but the non-poor are getting richer at a faster rate than the poor are.

The fact that inequality and poverty could move in opposite directions - for example, inequality rising while poverty is falling - matters not only for analytical purposes but also for policy purposes. Here are two contexts in which it has been shown to make a difference.

At a conference I attended in Mexico City, then-President Vicente Fox said in his opening address that the emphasis of his administration would be to "combat poverty." After the President left to attend to other matters, his Minister for Social Security addressed us, stating that the government's principal aim was to "combat poverty and inequality and redistribute." It is easy to think of policies that would combat poverty and yet raise inequality. It is also easy to think of redistributive policies that would combat inequality but increase poverty. The same policies would not necessarily be chosen by the 
President and the Minister. Many of us were left confused about what the government of Mexico was really trying to do.

As a second example, I would cite a public debate on inequality, poverty, and economic growth in which I participated. Writing in The Economist magazine, Robert Wade of the London School of Economics stated, "The global distribution of income is becoming ever more unequal. That should be a matter of greater concern than it is." The Economist replied editorially, "Another of Mr. Wade's arguments [is] that inequality is a bad thing in itself, regardless of the extent of poverty. Many people would agree with that - though it has some strange implications. One is that you could regard a country with more equality as a greater success than another, even if the egalitarian country had not merely lower incomes on average, but also more people in absolute poverty."

Both Wade and The Economist manifested a greater concern for inequality than for poverty, a view that I did not (and do not) share. Accordingly, I wrote in a published letter to The Economist: "What Mr. Wade, The Economist, and the rest of us all seek is a world in which both inequality and poverty are falling. But inequality is rising as poverty is falling. Are things getter better or worse? Reasonable people can and do disagree." Three weeks later, The Economist published a cover story entitled "Does Inequality Matter?" with the leading headline: "The new rich may worry about envy, but everyone should worry about poverty." The article continued: "Helping the poor, the truly poor, is a much worthier goal than merely narrowing inequalities."

Helping the truly poor is indeed a most laudable goal. In my view, inequality and poverty are not of equal importance. I do not see a compelling economic case for reducing inequality per se. I do see a compelling ethical reason to lower poverty: economic misery is a blight that deserves to be lessened and ultimately eradicated everywhere. My preference is to regard inequality instrumentally: it is all right for inequality to rise if the increase in inequality causes poverty to fall. I know that this is a personal value judgment, and while many will agree with it, many others will not. 


\section{What About Inequality? What Is It? How Concerned Should We Be About It?}

Nearly everyone is concerned about economic inequality. The question is, how concerned should we be. Before you jump to an answer, I would ask you to think about a very fundamental question: Do inequality measures measure inequality? ${ }^{10}$

In order for this question to make sense, we must recognize that "inequality" and "inequality measures" are not necessarily the same thing. ${ }^{11}$ The following thought experiment will help sharpen your intuition: ${ }^{12}$

Suppose there is a society consisting of $\mathrm{n}$ people. There is one rich person and n-1 identical poor people. One by one, some of those who were poor acquire the same income as the rich person, so that eventually there are n-1 (identical) rich people and just one poor person. What happens to inequality in this process?

Possible answers are:

- Inequality increases continuously.

- Inequality decreases continuously.

- Inequality at first increases and then decreases.

- Inequality at first decreases and then increases.

- Inequality remains the same throughout.

- None of the above.

When this question was administered experimentally, Amiel and Cowell obtained the following responses:

\footnotetext{
10 This is the title of a paper I published in 1998.

${ }^{11}$ Although if you say that inequality is the Lorenz curve, the Gini coefficient, the 90:10 ratio, or some other measure, then for you that inequality measure measures inequality tautologically.

12 The precise phrasing given below comes from Amiel and Cowell (1994). The issue was addressed previously in Fields $(1993,1998)$ and Temkin (1986).
} 
- $7.5 \%$ said that inequality increases continuously.

- $20.5 \%$ said that inequality decreases continuously.

- $19.9 \%$ said that inequality at first increases and then decreases.

- $36.7 \%$ said that inequality at first decreases and then increases.

- $11.2 \%$ said that inequality remains the same throughout.

- $4.1 \%$ answered none of the above.

The fact that the responses are so widely scattered with no single answer receiving a majority indicates that different people have very different opinions about what inequality is.

Now let me ask: what happens to inequality in this process as you see it?

Now that you have thought about "inequality", let me tell you about "inequality measures." Here is how they behave in the growth process described here:

- For the income share of the poorest person, inequality increases.

- For the income share of the richest person, inequality decreases.

- For the Gini coefficient, Theil's two measures, the coefficient of variation, the Atkinson index, the log-variance, and the income share of the poorest $\mathrm{X} \%$, inequality at first increases and then decreases.

- For the income share of the richest $\mathrm{Y} \%$, inequality at first decreases and then increases.

- For the ratio of the high income to the low income, inequality remains the same throughout.

Again, what do you see?

Here are some other questions to think about. If you see inequality rising and then falling in this process, do you see inequality reaching a maximum at $50 \%$ ? Similarly, if you see inequality falling and then rising in this process, do you see inequality reaching a minimum at $50 \%$ ? If your answer to either of these questions is "yes," you would surely want to know whether the standard inequality measures behave in the way you would 
like. The answers may surprise you: only the log-variance reaches a maximum at $50 \%$, and no standard inequality measure reaches a minimum at $50 \%$. The fact that only the log-variance reaches a maximum at $50 \%$ is problematical, because the log-variance is not Lorenz-consistent. ${ }^{13}$ If you believe in Lorenz-consistency and in a turning point at $50 \%$, you are in trouble - no standard inequality measure measures inequality for you.

I would draw two conclusions from these findings. The first is that the inequality about which we are supposed to be so concerned is itself a quite amorphous idea. The second conclusion, which follows from the first, is that the inequality measured by Lorenz curves, Gini coefficients, and other standard inequality measures should not necessarily be at the center of income distribution research or policy debate.

But if the inequality as usually measured is not to be at the forefront, what should be? In the next section, I offer some alternatives.

\section{Alternatives to Concentrating on Inequality as Usually Measured}

The most straightforward alternative is to retain the focus on income inequality but to switch the focus from Lorenz curves and Gini coefficients to the ratio of high incomes to low incomes. In the growth process discussed in the last section, inequality changes because of the changing numbers of people in the high-income and low-income groups, not because of changes in the high incomes and low incomes themselves. One thing that could be done when there are two well-defined groups, one high-income and one low-income, is to take the ratio of the two incomes, for example, the 90:10 ratio.

A second alternative is to focus on the inequality between salient groups. The groups that might be compared could be male and female workers, children from different social classes, advanced and backward regions, indigenous peoples vs. others, persons of different ethnicities, and so on. This issue is important both because of the

\footnotetext{
${ }^{13}$ See Foster and Ok (1999) for an in-depth analysis of this point and its implications.
} 
importance of group membership to individual identity (George Akerlof and Rachel Kranton, 2000) and because of the relationship between polarization between groups ( a statistical concept) and inter-group conflict (Joan Maria Esteban and Debraj Ray, 1999).

A third alternative is to concentrate on equality of opportunity. Another editorial opinion expressed by The Economist merits discussion here.

In addition to professing a concern for poverty, The Economist has also stressed the importance of setting ground rules so as to assure equality of opportunity. They maintain that "a long ladder is fine, but it must have rungs." More specifically: "Inequality is not inherently wrong - as long as three conditions are met: First, society as a whole is getting richer. Second, there is a safety net for the very poor. And third, everybody, regardless of class, race, creed or sex, has an opportunity to climb up through the system."

I agree that these are among the right conditions, and I see them as not at all being fulfilled. What I do see is that too many countries in the world are experiencing little or no economic growth, ${ }^{14}$ the safety net for the poor is in tatters if in fact a net is there at all, ${ }^{15}$ and opportunities for upward mobility are severely limited. ${ }^{16}$

In addition, inequality may be of concern for an additional reason: high inequality may slow economic growth, and the two together (high inequality and slow economic growth) may limit the rate of poverty reduction. But does it? An exceptionally careful review of the evidence by Abhijit Banerjee and Esther Duflo (2003) reveals no robust evidence showing that inequality is either a) bad for economic growth or b) good for economic growth either.

\footnotetext{
${ }^{14}$ Twenty-seven countries had per capita GDP growth of $1.0 \%$ or less according to the latest World Bank figures (World Bank, 2007).

${ }^{15}$ See, for instance, a description of the ILO's Global Campaign on Social Security and Coverage for All, available online at www.ilo.org/public/english/protection/socsec/pol/campagne/index.htm.

${ }^{16}$ Inequality of opportunity has been studied by John Roemer (1998D), Roland Bénabou and Efe Ok (2001), and World Bank (2006), among others.
} 
Equality of opportunity is important. If people feel that others are getting ahead while they are not, they make take matters into their own hands, bringing economic growth to a crashing halt or worse. ${ }^{17}$

A fourth alternative is to move away from inequality and focus on poverty reduction. In the classic paper by Anthony Atkinson (1970), the class of inequality measures

$$
A_{\varepsilon}=\left\{\begin{array}{l}
1-\left[\frac{1}{n} \sum_{i=1}^{n}\left(\frac{x_{i}}{\mu_{x}}\right)^{1-\varepsilon}\right]^{1 /(1-\varepsilon)} \quad \varepsilon>0 \\
1-\prod_{i=1}^{n}\left(\frac{x_{i}}{\mu_{x}}\right)^{1 / n} \varepsilon=0
\end{array}\right.
$$

involves the parameter $\varepsilon$. Atkinson calls this parameter "the degree of inequality aversion" an notes that as it increases, we attach more weight to transfers at the lower end of the distribution and less weight to transfers at the top. Yet, $\varepsilon$ might just as easily have been called "the degree of aversion to poverty"; as Atkinson notes, in the limit, $\varepsilon \rightarrow \infty$ gives the function $\min _{\mathrm{i}}\left\{\mathrm{y}_{\mathrm{i}}\right\}$, which only cares about the income of the poorest. Caring only about the poor is what Amaryta Sen (1976) has dubbed the "focus axiom." I believe a strong case can be made for caring considerably more about the poor than about others.

From a policy point of view, a concern with poverty reduction would emphasize two major channels. One would be mechanisms to enable the poor to earn their way out of poverty. ${ }^{18}$ The other would be targeted social spending and public services. ${ }^{19}$

\footnotetext{
${ }^{17}$ A perceptive analysis of this possibility, still relevant today, is the work of Albert Hirschman and Michael Rothschild (1976). Perhaps one of the most horrible cases of people taking matters into their own hands is what happened in Uganda under Idi Amin.

18 "Earning Their Way Out of Poverty" is the title of my next book.

${ }^{19}$ This topic is treated at length in World Bank (2004).
} 


\section{So How Much Should We Care About Income Inequality?}

Based on the preceding, my own views on how much attention should be given to inequality change in the course of economic growth can be summed up as follows:

First, do not worry much about what Lorenz curves, Lorenz-consistent inequality measures, and most other standard inequality measures are telling us.

Second, worry some about what the ratio of high incomes to low incomes is telling us.

Third, worry more about the inequality between salient groups.

Fourth, worry even more about inequality of opportunity, especially by socioeconomic origin.

And fifth, worry the most about poverty.

Specifically, from a policy point of view, I would urge governments to declare poverty, not inequality, to be the principal concern, precisely as President Fox did. I would want priority to be given to policies to reduce poverty by focusing economic growth and other efforts on the lower tail of the income distribution. I would also stress policies aimed at improving equality of opportunity. Such a program might involve:

a) Improving the ability of the poor to earn their way out of poverty, be it in wage employment or in self-employment; b) Upgrading workers' productive skills and abilities; c) Strengthening social protection for the very poor; and d) Offering improved opportunities to the lower classes.

Such choices are consequential. The fate of hundreds of millions of economically miserable people in the world lies in the balance. 


\section{References}

Akerlof, George A. and Kranton, Rachel E. "Economics and Identity," Quarterly Journal of Economics, 2000, 115 (August), pp. 715-753.

Amiel, Yoram and Cowell, Frank. "Inequality Changes and Economic Growth," in W. Eichhorn, ed., Models and measurement of welfare and inequality. Berlin: Springer, 1994.

Atkinson, Anthony B. "On the Measurement of Inequality." Journal of Economic Theory. 1970, 2(3).

Banerjee, Abhijit V. and Duflo, Esther. "Inequality and Growth: What Can the Data Say?” Journal of Economic Growth. 2003, 8, pp. 267-299.

Baulch, Bob and McCulloch, Neil. "Tracking Pro-Poor Growth," Institute of Development Studies, University of Sussex, processed, 2000.

Bénabou, Roland and Ok, Efe. "Social Mobility and the Demand for Redistribution: the POUM Hypothesis.” Quarterly Journal of Economics. 2001, 116(2), pp. 447-487.

Bhalla, Surjit S. Imagine there's no country. Washington: Institute for International Economics, 2002.

Deininger, Klaus and Squire, Lyn. "New Ways of Looking at Old Issues: Inequality and Growth.” Journal of Development Economics 57(2): pp. 259-287.

Duclos, Jean-Yves and Wodon, Quentin. "What Is 'Pro-Poor?” Université Laval, CIRPEE Working Paper 04-25, 2004.

Esteban, Joan Maria and Ray, Debraj. "Conflict and Distribution.” Journal of Economic Theory, 1999, 87, pp. 379-415.

Fields, Gary S. "Inequality in Dual Economy Models," The Economic Journal. 1993, 103, pp. 1228-1235.

Fields, Gary S. "Do Inequality Measures Measure Inequality?” in Stephen Jenkins, Arie Kapteyn, and Bernard M.S. van Praag, eds., The distribution of welfare and household production: international perspectives. Cambridge: Cambridge University Press, 1998, pp. 233-249.

Fields, Gary S. Distribution and Development: A New Look at the Developing World. Cambridge, MA: MIT Press and Russell Sage Foundation, 2001.

Fields, Gary S. "Does Income Mobility Equalize Longer Term Incomes? New Measures of an Old Concept," Cornell University, processed, 2005. 
Foster, James E. and Ok, Efe A. "Lorenz Dominance and the Variance of Logarithms." Econometrica. 1999, 67(4), pp. 901-907.

Ghose, Ajit K. Jobs and incomes in a globalizing world. Geneva: International Labour Office, 2003.

Harberger, Arnold. "Monetary and Fiscal Policy for Equitable Economic Growth," in Vito Tanzi and Ke-Young Chu, eds., Income distribution and high-quality growth. Cambridge and London: MIT Press, 1998.

Hirschman, Albert and Rothschild, Michael. "The Changing Tolerance for Income Inequality in the Course of Economic Development." Quarterly Journal of Economics. pp. 544-566, 1973.

International Finance Corporation, Paths out of poverty. Washington: IFC, 2000.

Kakwani, Nanak and Pernia, Ernesto. "What Is Pro-Poor Growth?” Asian Development Review. 18(1), pp. 1-16, 2000.

Kraay, Aart. "When Is Growth Pro-Poor? Evidence from a Panel of Countries." Journal of Development Economics. 2006, 80, pp. 198-227.

Leipziger, Danny. What's old and what's new in development policy? Available online at http://info.worldbank.org/etools/bspan/PresentationView.asp?PID=1496\&EID=711

Milanovic, Branko. Worlds apart: Measuring international and global inequality. Princeton, NJ: Princeton University Press, 2005.

Ravallion, Martin. Pro-poor growth: a primer. World Bank Policy Research Working Paper 3242, March, 2004.

Roemer, John E. Equality of Opportunity. Cambridge, MA: Harvard University Press, 1998.

Sen, Amartya K. "Poverty: An Ordinal Approach to Measurement." Econometrica. 1976, 44, pp. 219-231.

Summers, Lawrence. "Comment," in Vito Tanzi and Ke-Young Chu, eds., Income distribution and high-quality growth. Cambridge and London: MIT Press, 1998.

Temkin, L.S. "Inequality.” Philosophy and Public Affairs. 1986, 15, pp. 99-121.

United Nations, Human development report 2004. New York: United Nations, 2005.

Wolf, Martin. Why globalization works. New Haven: Yale University Press, 2004. 
World Bank. 2005 World development indicators. Washington, DC: World Bank, 2005.

World Bank. World development report 2004. Washington, DC: World Bank, 2004

World Bank. World development report 2006. Washington, DC: World Bank, 2006.

World Bank. World development report 2007. Washington, DC: World Bank, 2007. 